EDUCATION

Research, Inovorition and Solutions on Hine $^{\theta}$
PSYCHOLOGY

$1+D+i$
Electronic Journal of Research

in Educational Psychology

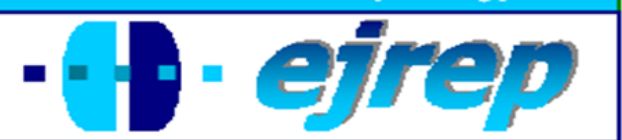

\title{
Learning sensory modalities and educational characteristics of Greek dyslexic and non-dyslexic university students
}

\author{
Aglaia Stampoltzis ${ }^{1}$, Ekaterini Antonopoulou ${ }^{2}$, \\ Elena Zenakou $^{2}$, Sofia Kouvava ${ }^{1}$ \\ ${ }^{1}$ Department of Primary Education, University of Athens \\ ${ }^{2}$ Department of Home Economics \& Ecology, \\ Harokopio University, Athens
}

\section{Greece}

Correspondence: Aglaia Stampoltzis. 3, Androu street. 15121 Athens. Greece. E-mail: 1stamp@ambio.gr (C) Education \& Psychology I+D+i and Editorial EOS (Spain) 


\begin{abstract}
Introduction. Dyslexia has been shown to affect the learning ability of individuals who experience difficulties in processing written information and developing effective study skills.

Method. In the present study we assessed the relationship between dyslexia, the learning sensory modalities and educational characteristics in 20 dyslexic and 40 non-dyslexic Greek university students. The students' educational characteristics were evaluated through the Academic and Professional Profile Questionnaire. Their learning sensory modalities were identified using the Learning Preferences Test.

Results. The results revealed that dyslexic students differ from their non-dyslexic peers in their preferred sensory learning style. Kinaesthetic learning was the most favoured by the dyslexic students, while the non-dyslexic students favoured visual learning. Dyslexic students rated themselves academically worse and less competent in written work than their nondyslexic peers at school. Correlations were found between sensory learning preferences and certain educational characteristics.
\end{abstract}

Discussion. The results of the present study are discussed in the light of dyslexia, learning style theory and quality of teaching and learning.

Keywords: dyslexia, Greek students, learning sensory modalities, learning style.

Received: 01/11/10 Initial Acceptance: 01/12/10 Definitive Acceptance: 07/29/10 


\section{Modalidades sensoriales de aprendizaje y características educati- vas de alumnos universitarios griegos disléxicos y no disléxicos}

\section{Resumen}

Introducción. Se ha demostrado que la dyslexia afecta a la capacidad de aprendizaje de aquellos que tienen dificultades en el procesamiento de la información escrita y afecta el desarrollo efectivo de habilidades de estudio.

Método. En el presente estudio evaluamos la relación entre dyslexia, modalidades de aprendizaje sensorial y características educativas en 20 alumnos universitarios dislexicos y 40 no disléxicos. Las características educativas fueron evaluadas a través del Cuestionario de Perfil Académico y Profesional. La modalidades de aprendizaje sonsorial fueron identificadas utilizados el Test de Preferencias de Aprendizaje.

Resultados. Los resultados señalan que los estudiantes disléxicos difieren de sus compañeros no disléxicos en cuanto a las preferencias de estilo de aprendizaje sensorial. El aprendizaje cinestésico era más preferido porlos estudiantes disléxicos en tanto que, los no disléxicos, preferían al aprendizaje visual. Los estudiantes con dislexia se calificaron como peores académicamente y menos competentes en tareas escritas que sus compañeros no disléxicos. Las correlaciones muestran relación entre las preferencias de aprendizaje sensorial y determinadas características educativas.

Discusión y conclusiones. Los resultados del presente estudio se discuten a la luz de la dislexia, las teorías sobre estiolos de aprendizaje y la calidad del proceso enseñanza-aprendizaje.

Palabras clave: dislexia, alumnado, modalides de aprendizaje sensorial, estilo de aprendizaje.

Recibido: 11/01/10 Aceptación Inicial: 12/01/10 Aceptación Definitiva: 29/07/10 


\section{Introduction}

It is widely accepted that dyslexia is a condition that affects learning in individuals throughout lifespan and often is associated with specific learning patterns and strategies (Mortimore, 2008). It is also a general consent that managing dyslexia and learning diversity in higher education is an important issue in terms of creating suitable learning environments and encouraging all students to develop their personal learning potential and the necessary academic skills (Jamieson \& Morgan, 2008). Research evidence on dyslexia and its relationship to a specific learning style is limited and less than conclusive (Mortimore, 2008; Mortimore \& Crozier, 2006). Furthermore, empirical evidence regarding the range of teaching patterns, learning approaches and study strategies that might develop in a supportive and inclusive academic environment is also scarce.

The present study attempts to advance our knowledge on the possibility that dyslexia in university students is associated with preference to a specific sensory learning style or not and thus sensory learning preference may or not be a distinctive dimension between dyslexic and non-dyslexic condition. Moreover, it examines whether students with dyslexia exhibit particular perceptions about personal academic competence and if these perceptions differ from those reported by non-dyslexic students. The long-term aim of this research is to contribute to a general evidence-based notion towards an inclusive academic environment that promotes quality and variety, encourages flexible learning approaches and provides a wide range of multisensory learning opportunities to all students.

\section{Learning styles}

The learning style is simply an 'approach' or 'way' of learning. A comprehensive definition is provided by Mortimore (2000), who draws upon research into learning behaviour in order to define the learning style as an individual's characteristic behaviour and a relatively consistent way of processing incoming information of all types from the environment.

Conflicting views about learning underpin the major and most widely known models of learning styles. A review by Coffield, Moseley, Eccleston, \& Hall (2004) revealed that learning style theorists have devised about 70 constructs (or models). Some models are rooted 
in theories of personality and motivation; others are related to areas of the brain. Some are developmental and follow Piaget (1970) in suggesting that style evolves from stage to stage throughout a learner's lifetime to achieve maturity. Each model is accompanied by its own assessment methodology and with suggestions for educational applications. Coffield et al. (2004) extensive review of theories and models of learning styles emphasizes the complexity of the learning style field and highlights the importance of conducting research which examines not only how people learn but also how to enhance people's learning and enrich diverse learning environments.

Currently, learning styles are assessed by using inventories, questionnaires, interviews, behavioural observation, the creation of profiles or a combination of all the above (García-Ros, Pérez \& Talaya, 2008; Mortimore, 2008). However, there is a strong controversy as to whether these techniques are effective measures of learning styles and also whether learning style is a measurable characteristic or not (Coffield et al., 2004).

The Dunn and Dunn (1999) learning styles model offers a well-researched example of a model which identifies a combination of elements that may affect, positively or negatively, how well each individual achieves and performs in educational and work-based learning environments. The first part of the Dunn and Dunn model (1999) provides a way to assess people's preferred way of learning through a specific sensory modality or a combination of modalities. It focuses on the perceptual elements of learning, in other words, how one is predisposed for learning and retaining new knowledge skillfully. The three senses, which people primarily use to take in information, are Visual, Auditory and Kinesthetic or Tactile.

Visual learners like to learn through written language. They remember what has been written down and do better with charts, pictures, displays and other visual material. Auditory learners usually transfer information through listening. They talk to themselves a lot. They need to verbalise the questions and develop an internal dialogue. Kinesthetic learners usually learn through moving, doing and touching. Their learning involves hands-on experience. They tend to lose concentration if there is little or no external stimulation or movement (Prashnig, 2004). Learners use all three ways to receive information. However, one or more of these perceptual preferences are normally dominant. The perceptual elements of the Dunn and Dunn (1999) model allow individuals to acquire comprehensive picture of their unique learning and strengths and preferences. 
Although there is no single accepted model of learning style and despite the questionable reliability of the models, learning style theory continues to be applied in education, both in practice and through research studies (Dunn \& Dunn, 1999; Riding \& Rayner, 1998). Several studies suggest that whenever possible, one should use his/her strongest perceptual preference first. This will help ensure that individuals retain more information for later recall (Dunn \& Dunn, 1999; Given \& Reid, 1999). Research still has to answer many questions, especially concerning the reliability and validity of the models used. The present study aims to provide insight into the relationship between dyslexia and learning sensory modalities.

\section{Dyslexia}

Dyslexia has been described as a language-based disorder (Orton Dyslexia Society, 1994). Recent definitions give a broader picture of the difficulties and differences encountered among dyslexic people in contrast to non-dyslexics (Soriano, 2004). The British Dyslexia Association (2005: 19) describes dyslexia as 'a combination of abilities and difficulties that affect the learning process in one or more of reading, spelling, writing and sometimes numeracy. It is a persistent condition and accompanying weaknesses may be identified in areas of speed of processing, short-term memory, organisation, sequencing and motor skills. Dyslexia can occur despite normal intellectual ability and teaching and it is constitutional in origin. Some learners have very well developed creative skills, others have strong interpersonal skills, some have no outstanding talents, all have strengths' (p.19).

The Dyslexia Institute also provides an expanded and clarified definition which gives a clear picture of the types of learning differences often encountered by dyslexic students. 'Specific learning difficulties (dyslexia) can be defined as organising or learning deficiencies which restrict the students' competencies in information processing, in motor skills and working memory, so causing limitations in some or all of the skills of speech, reading, spelling, writing, essay writing, numeracy and behaviour (Pumfrey \& Reason, 1991: 14).

The most recent definition of dyslexia is included in the Rose report (2009:10). The new element offered by this definition is that 'dyslexia is best thought of as a continuum, not a distinct category, and there are no clear cut-off points. It occurs across the range of intellectual abilities. A good indication of the severity and persistence of dyslexic difficulties can be 
gained by examining how the individual responds or has responded to well founded intervention' (p.10). This recent definition reflects the move from the 'deficit' model of dyslexia which portrayed the individual beset with difficulties and incapacities derived from their condition to the 'empowerment' model of dyslexia which emphasizes the various kinds of support and multisensory teaching methods to accommodate the needs of dyslexic students (Reid \& Kirk, 2001).

In the Rose report (2009) effective interventions for children with literacy difficulties or dyslexia are those which 'personalise learning' by matching provision to meet children's individual needs, quicken their pace of learning, thus narrowing the attainment gap with their typically developing peers.

\section{Dyslexia in higher education}

Most of the research on dyslexia has concentrated on the population of dyslexic children. As Frith (1997) states, dyslexic children grow up into dyslexic adults and many, whose reading has developed sufficiently for them to gain the appropriate qualifications, move on into higher education. According to the National Working Party on Dyslexia in Higher Education (Singleton, 1999) and the Higher Education Statistics Agency (2006) dyslexia is a factor which affects the learning experience of a significant and increasing number of higher education students. This is partly the result of the increased diagnosis of the condition, and of students and parents wishing to use every means possible to gain advantage.

The needs of dyslexic students in higher education have been documented by Gilroy and Miles (1996) and Farmer, Riddick, and Sterling (2002). Intuitively, students with dyslexia who face a variety of academic difficulties may be expected to use different ways of processing information by exhibiting a variety of learning styles. In addition, students with dyslexia have a range of persistent literacy and study difficulties. The challenges posed by a different type of education, and the frequently large-scale and impersonal environment of a university, are exacerbated by the memory, time and spatial difficulties that beset many dyslexic students (Greenbaum, Graham \& Scales, 1996; Mortimore \& Crozier, 2006). 


\section{Learning styles and dyslexia}

Coffield et al., (2004) and Mortimore (2005, 2008) draw attention to the controversy and complexity of learning styles theories and particularly their implications for teaching students with dyslexia.

West (1997) claimed that dyslexia might be linked with particular visuo-spatial skills and cited Einstein and Leonardo da Vinci as examples of gifted individuals who might have been dyslexic. It has been suggested (Morgan \& Klein, 2000) that dyslexic individuals are disadvantaged by the way in which academic material is presented, in that it does not suit their visuo-spatial learning style.

The selection of dimensions of the learning style construct provides an opportunity to examine the claim, which seems to have been accepted by some researchers (West, 1997), that there is some relationship between visuo-spatial strategies or strengths and dyslexia. This hypothetical relationship remains with little published empirical research to support it. Research still has to answer many questions about possible links between flexible learning styles and academic success. However, there is support for the suggestion that people who are aware of their learning style are more likely to succeed in an academic setting which caters for different learning styles (Riddick, Farmer \& Sterling, 1997; West, 1997).

Furthermore, research into learning styles and dyslexia is limited with different methodological bases. A small-scale study conducted by Exley (2003) examined the preferred learning style of seven dyslexic students and whether teaching to students' preferred learning style would improve their performance in literacy and numeracy. Exley (2003) states that five out of seven students preferred a visuospatial/kinaesthetic learning style which supports the theory of West (1997). These students showed improvement in the given tests while the other two did not improve significantly. Thus, the researcher suggests that students with dyslexia can improve their performance, attainment and the way they feel about themselves if they are encouraged to use their preferred learning style.

Mortimore (1998) conducted a small scale study comprising 15 students with dyslexia and 15 without, using the Cognitive Styles Analysis (Riding, 1991) to examine the extent to 
which those with dyslexia favour visual processing approaches over the verbal ones. This study did suggest some relationship between visual style labels and dyslexia but these findings were not replicated in her 2003 study of 117 students (60 dyslexic and 58 controls). The latter examined the relationship between dyslexia and learning style in male university students and determined the impact dyslexia, cognitive style and mode of presentation might have upon success levels at a university task. The study yielded a number of interesting results. Although no significant differences in learning style were found between dyslexic and non-dyslexic students, dyslexic students experienced more difficulty in retaining and using information from the standard lecture mode (i.e. auditory learning). Dyslexia status was independent of cognitive style, at least for this sample and this measure of style.

Reid and Kirk (2001) suggest that instructions for dyslexic people can be provided either visual, auditory, kinesthetic or tactile. It is important that the instructions are provided in a variety of ways because if they are given purely orally, the learner is then relying on the auditory modality. Many dyslexic learners are stronger in other modalities and may indeed have a weakness in the auditory modality. Many are in fact stronger in the visual modality so they should be allowed to make visual images or mind maps as they are learning, or indeed the information should be provided visually.

\section{Educational characteristics, past experiences and dyslexia}

A growing number of dyslexic students are enrolled in universities and various studies have examined their academic adjustment and the challenges they face. The most persistent difficulties that dyslexic students report include difficulties in writing assignments and taking written exams, spelling difficulties, memorising names and facts, note-taking difficulties, numeracy problems, difficulty in daily organisation and underdeveloped study skills (Gilroy \& Miles, 1996; Mortimore \& Crozier, 2006; Reid \& Kirk, 2001; Singleton, 1999).

Cohen (1984) studied 28 learning disabled students. She found strong correlations between the subjects' self-reports on their literacy difficulties and their performance on standardised reading, spelling and writing tests, indicating that they had a realistic picture of their own difficulties. Despite the high level of awareness, $76 \%$ of the students still reported difficulties with their grammar, spelling and punctuation, $72 \%$ reported difficulties with taking adequate notes and $76 \%$ reported difficulties with reading and writing exam papers. 
In addition, Riddick, Sterling, Farmer, and Morgan (1999) examined the self-esteem, anxiety and educational histories of 16 dyslexic students and 16 matched controls. On the standardised anxiety measures, there were no significant differences between the groups. However, the dyslexic group reported themselves as feeling more anxious and less competent in their written work at school than the controls and rated themselves at university as less competent both in their written work and in their academic achievements. Several dyslexic students also spoke about how negative recollections of their time at school still affected how they felt and performed when faced with various literacy tasks.

A common trend identified in the literature is that a large number of dyslexic students recall negative memories from primary and secondary school with limited acknowledgement and understanding of dyslexia. It is not clear whether the students' feelings of anxiety are primarily linked to the students' present performance at university or whether negative experiences in the past continued to have an adverse effect on the present (Edwards, 1994; Hellendoorn \& Ruijessenaars, 2000; Riddick et al., 1999).

In particular, in Mortimore and Crozier' study (2006) 136 male dyslexic students from 17 different British universities reported difficulties with a wide range of skills and academic tasks. They also reported that their difficulties were long lasting and had been experienced in primary and secondary school, although the pattern of these difficulties changed over time.

To bring together the trends reported in the literature, students' self-evaluations are important elements in the development of competence as a learner. The more accurately one is able to evaluate one's strengths and weaknesses the more likely it is that one can make positive changes (McLoughlin, Fitzgibbon \& Young, 1994; Scott, Scherman \& Philips, 1992). Given these considerations, a first premise might be for the student to understand their academic characteristics (Farmer, Riddick \& Sterling, 2002). Furthermore, it has been suggested that academic success demands a high level of persistence for dyslexic students who need to recognise, value and develop their particular learning preferences in order to fully utilise their strengths and circumvent their weaknesses (Singleton, 1999; Mortimore, 2005). 
Aims of the study

The present study aims to shed light on the relations between dyslexia, learning sensory modalities and educational characteristics of Greek undergraduate university students. It examines the educational characteristics of dyslexic students compared to their non-dyslexic peers. It is hypothesised that dyslexic students will be lower in their self-evaluations, higher in anxiety and more negative about their past and present educational experiences than the group of non-dyslexic students. Finally, the study seeks to trace possible links between educational characteristics and sensory learning preferences in both groups.

\section{Method}

\section{Participants}

Data were collected from 20 undergraduate dyslexic students and 40 undergraduate non-dyslexic students who were recruited from 3 Higher Education Institutions in Greece. All participants were volunteers contacted through student services or publicity posters. The dyslexic students had a formal diagnosis of dyslexia from a public psycho-educational centre or a public hospital and have obtained a re-evaluation of their difficulties within the last three years. Their formal diagnosis of dyslexia was based on the Wechsler Intelligence Scale for Children-III (WISC-III) or Weshler Adult Intelligence Scale (WAIS) profile, depending on their age, and a series of word-reading, writing and spelling attainment tests. They were also given the Revised Adult Dyslexia Checklist (Vinegrad, 1994) where they scored between 45 and 60 while the cut-off score for having a dyslexia type problem was 42 (Vinegrad, 1994).

The subject areas (course of study) of dyslexic students varied considerably. Dyslexic students studied economics $(n=5)$, engineering $(n=4)$, natural science subjects $(n=5)$, health sciences $(n=3)$, education $(n=2)$ and only one student $(n=1)$ studied art. The non-dyslexic students were recruited from the same university courses.

Particular attention was paid to match the two groups in terms of age, gender and social background. The dyslexic group consisted of 20 students. There were 10 men and 10 
women, aged 19 to 29 years $(\mathrm{M}=22.8, \mathrm{SD}=3.04$.) The non-dyslexic group consisted of 40 students. There were 16 men and 24 women, aged 19 to 30 years $(M=20.6, S D=1.82)$. No significant differences were found between the two groups with respect to the proportion of men and women $\left(\chi_{(1,59)}^{2}=0.54, \mathrm{p}>.05\right)$.

\section{Tests and materials}

The Academic and Professional Profile Questionnaire (Riddick, Farmer \& Sterling, 1997) is a self-report scale adapted in Greek and piloted before being used in the study. It comprised four sections as follows: Section 1: Personal information; Section 2: At school (ten questions); Section 3: After school (seven questions) and Section 4: At University (ten questions). Several items in the questionnaire asked the students to rate themselves in comparison to their peers on certain language skills such as writing and their level of anxiety. Students were asked to choose on a five-point scale between much worse, worse, about the same, better, much better.

The Learning Preferences Test (Zenakou, 2005) was used to assess the preferred learning styles of Greek university students. It was constructed on the basis of similar learning styles inventories such as those used by Wingate (2000) and, Dunn and Dunn (1999). It comprises 27 statements divided into 9 categories, which relate to the following learning preferences: learning, conversation, reading, self, remembering, writing, spelling, imagination and voice. Each category of three statements evaluates three different sensory modalities: visual, auditory and kinaesthetic. Students had to complete the test individually and give themselves a score of 3 for the truest statement, the score of 1 for the least true statement and the score of 2 for the remaining statement of the category. On the basis of their scores, students were categorised accordingly as Visuals, Auditory or Kinaesthetic. Internal reliability of the Learning Preferences Test was tested with the technique of Cronbach Alpha $(\alpha=.70, p<.01)$. Test-retest reliability was used to test the validity of the test. The test-retest reliability was calculated with Pearson correlational technique $(\mathrm{r}=.93, \mathrm{p}<.01)$.

\section{Procedure}

This study was part of a larger study collecting data on dyslexic and control students. All participants were seen individually by the researcher in a quiet place. The dyslexic stu- 
dents were given the Revised Adult Dyslexia Checklist (Vinegrad, 1994) to ensure that they still have dyslexia-type problems. Their scores fell within the range for dyslexic type problems, so all the 20 participants continued to the next phase of the research. The Academic and Professional Profile Questionnaire was given first. The Learning Preferences Test was administered next. At the end of the session explanations were given to those students who wanted to know more about their learning sensory modalities and how to take advantage of them in their learning situations.

\section{Results}

The preferred learning sensory modalities of dyslexic and non-dyslexic students are presented in Figure 1 below. Fifty percent of the dyslexic students favour the kinaesthetic learning style while $55 \%$ of non-dyslexic students favour the visual learning style. A small percentage of students in both groups demonstrated a mixed sensory modality. They scored equally on two or all modalities.

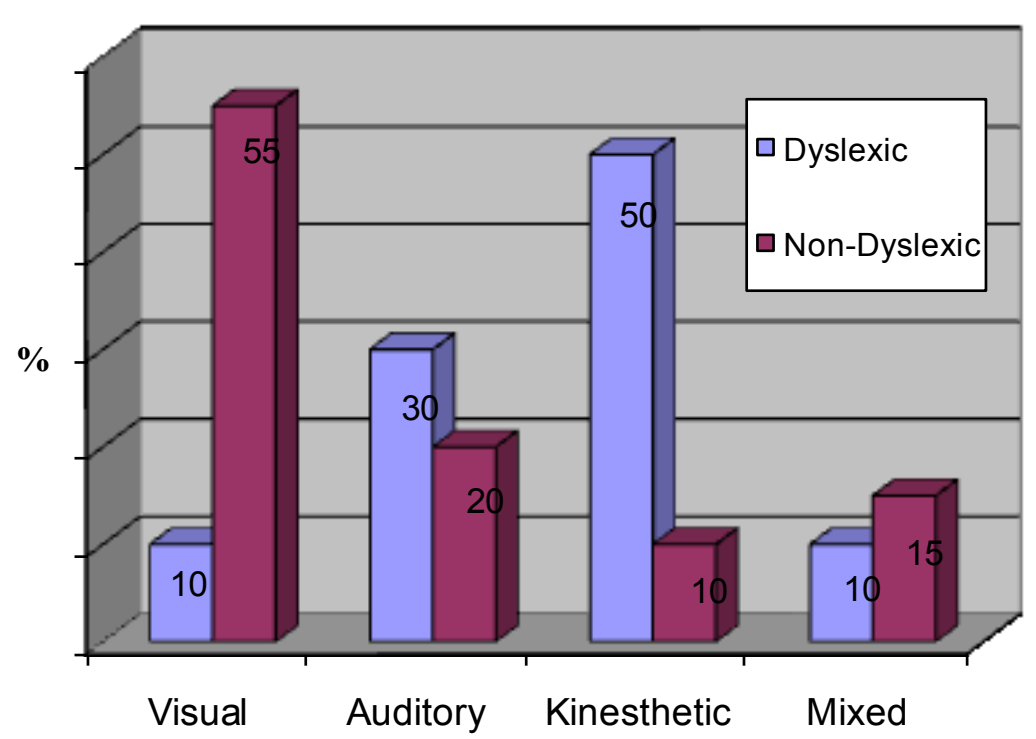

Figure 1. Learning styles of dyslexic and non dyslexic students

A chi-square analysis was performed to test for any significant differences in the sensory modalities for each group of students. The preferred learning style among the dyslexic students was kinaesthetic learning $\left(\chi_{(1,19)}^{2}=8.88, \mathrm{p}<.05\right)$, while the preferred learning style among the non-dyslexic group was visual learning $\left(\chi^{2}(1,39)=20, \mathrm{p}<.001\right)$. 
On the academic and professional questionnaire there were a number of statistically significant differences between the groups. The dyslexic group rated themselves on a scale of 1-5 as generally worse academically than their peers in both primary and secondary school, whereas the control group rated themselves generally as average or better than their peers. $T$ test analysis was performed and differences were significant at the $p<.001$ level (Table 1).

Table 1. Means and F scores of dyslexic and non-dyslexic students' educational characteristics

\begin{tabular}{ccccc}
\hline & Dyslexic & Non-Dyslexic & & \\
Variables & $(\mathrm{N}=20)$ & $(\mathrm{N}=40)$ & & \\
& Mean & Mean & $\mathrm{F}(1,59)$ & Significance \\
\hline Primary school performance & 2.74 & 4.58 & 57.08 & $.000 * *$ \\
Secondary school performance & 3.05 & 4.15 & 20.07 & $.000 * *$ \\
Writing ability in primary school & 1.95 & 2.88 & 27.09 & $.000 * *$ \\
Writing ability in secondary school & 2.05 & 2.55 & 4.93 & $.001 * *$ \\
Anxiety at School & 2.26 & 2.80 & 2.78 & .101 \\
Academic performance at university & 3.11 & 3.08 & 0.02 & .879 \\
Writing ability in university & 2.33 & 2.78 & 2.47 & .122 \\
Anxiety in university & 2.39 & 2.88 & 1.81 & .184 \\
\hline Note: $* p<.05^{* *} p<.001$ & & & &
\end{tabular}

Dyslexic students, unlike the controls, tended to rate their writing ability and overall academic performance (both in primary and secondary school) lower than their school peers $(p<.001)$. As far as academic performance and writing ability at university are concerned, no statistical significant differences were found between the two groups. It is possible that dyslexic students view themselves as equally competent as their non-dyslexic peers in terms of performance at the university level (Table 1).

To investigate possible links between learning sensory modalities and educational characteristics, correlations were calculated separately for each group (dyslexic and nondyslexic). As presented in Table 2, for the dyslexic group significant correlations were found between kinaesthetic learning and a) primary school performance $(\mathrm{r}=-.45, \mathrm{p}<.05)$, b) writing ability in primary school $(\mathrm{r}=-.46, \mathrm{p}<.05)$ and $\mathrm{c})$ writing ability in secondary school $(\mathrm{r}=-.70$, $\mathrm{p}<.01)$. A significant correlation was also observed between auditory learning and primary 
school performance $(\mathrm{r}=-.54, \mathrm{p}<.05)$. For the non-dyslexic group anxiety at school was significantly correlated with visual $(r=-.32, p<.05)$ and kinesthetic learning style $(r=-.36, p<.05)$.

Table 2. Correlation of learning styles and educational characteristics by group (dyslexic and non-dyslexic)

\begin{tabular}{lcccccc}
\hline & \multicolumn{3}{c}{ Dyslexic (N=20) } & \multicolumn{3}{c}{ Non-dyslexic (N=40) } \\
\hline & Visual & Auditory & $\begin{array}{c}\text { Kinest } \\
\text { hetic }\end{array}$ & Visual & Auditory & $\begin{array}{c}\text { Kinest } \\
\text { es- } \\
\text { thetic }\end{array}$ \\
$\begin{array}{l}\text { Primary school } \\
\text { performance }\end{array}$ & -.17 & $-.54^{*}$ & $-.45^{*}$ & -.08 & -.17 & -.21 \\
$\begin{array}{l}\text { Writing ability in } \\
\text { primary school }\end{array}$ & -.29 & -.13 & $-.46^{*}$ & -.15 & -.07 & -.05 \\
$\begin{array}{l}\text { Writing ability in } \\
\text { secondary school }\end{array}$ & -.05 & -.09 & $-.70^{* *}$ & .05 & -.00 & .11 \\
$\begin{array}{l}\text { Anxiety at school } \\
\text { Ante }\end{array}$ & .02 & -.17 & -.24 & $-.32^{*}$ & .07 & $-.37^{*}$ \\
\hline
\end{tabular}

Note: $* p<.05 \quad * * p<.001$

\section{Discussion}

The results indicated a significant difference in the preferred sensory learning modality of dyslexic and non-dyslexic students. It appears that dyslexic students prefer kinaesthetic learning which means that they learn best through doing and touching, through a hands-on approach, as a result of their need for activity and exploration. Non-dyslexic students, on the other hand, prefer visual learning which means that they learn best through visual stimuli (i.e. diagrams, illustrated text books, videos, flipcharts, hand-outs) and benefit most from the visual aids used during a typical university lecture. This finding seems to be in line with Exley's (2003) observation that the majority of the students in her study favoured a visuospatial/kinaesthetic learning style and improved their performance when they were taught to their preferred learning style. However, direct comparisons cannot be made given that the present study is based on self-report data and not learning performance data.

The difference in learning styles of dyslexic and non-dyslexic students offers some support to the hypothesis that dyslexic students process information and learn in different 
ways than their non-dyslexic counterparts (West, 1997). What is more, the learning style preference of the dyslexic students in our study partly agrees with Mortimore's (2003) conclusion that although no significant differences in learning style were found between dyslexic and non-dyslexic students, dyslexic students experienced more difficulty in retaining and using information from the standard lecture mode (auditory learning). It has been suggested (Morgan \& Klein, 2000; Reid \& Kirk, 2001) that dyslexic students may indeed have a weakness in the auditory modality, so they are disadvantaged by the way in which academic material is presented, in that it does not suit their visuospatial/kinaesthetic learning style. This suggestion seems reasonable according to the identified kinaesthetic learning preference of the dyslexic students in this sample. Different results can be explained by different methodologies used by the researchers and the variety of learning styles' constructs and measures (Coffield et al., 2004).

A second hypothesis tested under the present study was whether dyslexic students differ from the non-dyslexic ones in terms of reported academic performance and anxiety. This hypothesis came true only for the academic performance of dyslexic students. To be more specific, the dyslexic students rated themselves as less competent in their written work and in their academic performance than their non-dyslexic peers both in primary and secondary school. This conclusion has also been reported by Riddick et al. (1999) and Hellendoorn and Ruijessenaars (2000).

Turning to university level, dyslexic students view themselves to be as competent in writing ability as their university peers and felt equally anxious in comparison to them. This finding supports the idea that although the cognitive and functional difficulties of the dyslexic students persist in their adulthood, the negative emotional concomitants reduce considerably once individuals have left the competitive and high literacy demands of the school environment (Hellendoorn and Ruijessenaars, 2000; Riddick, Farmer \& Sterling, 1997). University seems to be a more sympathetic and less demanding environment, at least for this sample of Greek dyslexic students. The differences in the past educational experiences of the dyslexic students compared to the control group can be attributed to the nature of their dyslexia problem. Their improvement during the university years is an optimistic conclusion which is reported in the literature and may be explained as a result of compensation, persistence and hard work (Gilroy \& Miles, 1996; Riddick, Farmer \& Sterling, 1997). 
The negative correlations between kinaesthetic, auditory learning and certain educational characteristics in primary and secondary school for the dyslexic group suggest that teaching methods at school favour particular sensory modalities and children who do not prefer them encounter difficulties in certain aspects of academic learning. In addition, the preference of visual or kinaesthetic learning for the non-dyslexic students reduces their feelings of anxiety at school. These correlations suggest that the teaching methods at school mostly favour certain learning styles without taking account the variety of learning styles existing in a classroom. In recent years, more emphasis has been placed on the idea that the most effective learning would take place when instruction and learning style are matched (Given \& Reid, 1999). The school must create a flexible and rich learning environment to ensure that teaching does not always favour a particular learning style but it serves all students with various learning styles (Mortimore, 2000, 2008). Students with dyslexia can reach both academic and personal goals provided that their needs are recognised and that they are taught by multisensory, cumulative, sequential, progressive and step to step teaching methods (Rose, 2009).

The results of our study have shown the relationship between dyslexia, learning sensory modalities and educational characteristics. It reveals the importance of students' selfawareness about their learning preferences in order to monitor their learning process and become independent and successful learners. Although it is difficult for university staff to develop tailor made study programmes for their dyslexic students, they can maximize the learning opportunities of their students by integrating visual, auditory and kinesthetic or tactile elements of teaching. As Coffield et al. (2004) argue, one of the main aims of encouraging a metacognitive approach is to enable students to choose the most appropriate learning strategy from a wide range of options to fit a particular academic goal.

\section{Limitations and suggestions}

Our findings should also be viewed in light of two limitations. First, the results are limited by the relatively small groups of dyslexic and non-dyslexic students $(\mathrm{N}=20 \& \mathrm{~N}=40)$ from different disciplines who were volunteers contacted through student services. It may be worthwhile to continue/repeat this pilot study, with a larger sample of students.

Second, the students were asked to provide a single self-report on their preferred learning style and academic characteristics. A further study may use supplementary instruments 
proposed in the Coffield et al.'s report (2004) to measure students' learning styles and compare their academic characteristics with their formal academic achievements.

As mentioned by several researchers (Fuller, Healey, Bradley, \& Hall, 2004; Mortimore, 2008) dyslexia and learning style is a fruitful area of research. The data of the present study seem to support the swift from the 'deficit model' of dyslexia to the 'personal empowerment' model of dyslexia, seeking to identify ways to support learners in the pursuit of their personal and academic goals, not only by diagnosing how dyslexic students learn, but by showing them how to enhance their learning.

\section{References}

Coffield, F., Moseley, D., Hall, E. \& Ecclestone, K. (2004) Should we be using Learning Styles? What research has to say to practice. London: Learning and Skills Research Centre.

Cohen, J. (1984). The learning disabled and university student: Signs and initial screening. NASPA Journal, 21, 22-31.

Dunn, R. \& Dunn, K. (1999). The complete guide to the learning style inservice system. Boston: Allyn \& Bacon.

Edwards, J.H. (1994). The scars of dyslexia: Eight case studies in emotional reactions. London: Cassell.

Exley, S. (2003). The effectiveness of teaching strategies for students with dyslexia based on their preferred learning styles'. British Journal of Special Education, 30(4), 213-220.

Farmer, M., Riddick, B. \& Sterling, C. (2002). Dyslexia and inclusion: Assessment \& support in higher education. London: Whurr.

Frith, U. (1997). Brain, mind and behaviours in dyslexia. In C. Hulme \& M. Snowling (Eds.) Biology, cognition and intervention (pp. 1-19). London: Whurr.

Fuller, M., Healey, M., Bradley, A \& Hall, T. (2004). Barriers to learning: a systematic study of the experience of disabled students in one university. Studies in Higher Education, 29, 303-318.

García-Ros, R., Pérez, F. \& Talaya, I. (2008). New university students instructional preferences and how these relate to learning styles and motivational strategies. Electronic Journal of Research in Educational Psychology, 6(3), 547-570.

Gilroy, D.E. \& Miles, T.R. (1996). Dyslexia at college. (2 ${ }^{\text {nd }}$ ed.). London: Roultledge. 
Given, B. K \& Reid, G. (1999). Learning styles: a guide for teachers and parents. St-Anneson-Sea: Red Rose Publications.

Greenbaum, B., Graham, S. \& Scales, W. (1996). Adults with learning disabilities: Educational and social experiences during college. Exceptional Children, 61, 460-471.

Hellendoorn, J. \& Ruijssenaars, W. (2000). Personal experiences and adjustment of Dutch adults with dyslexia. Remedial and Special Education, 21(4), 227-239.

Higher Education Statistics Agency (2006). Table 11b-First year UK domiciled HE students by qualification aim, mode of study, gender, disability 2005/06. [online at: http://www.hesa.ac.uk ].

Jamieson, C. \& Morgan, E. (2008). Managing Dyslexia at University: A Resource for Students, Academic and Support Staff. London: Routledge.

McLoughlin, D., Fitzgibbon, G. \& Young, V. (1994). Adult dyslexia: Assessment, counseling and training. London: Whurr.

Morgan, E. \& Klein, C. (2000). The dyslexic adult in a non-dyslexic world. London: Whurr.

Mortimore, T. \& Crozier, W. R. (2006). Dyslexia and difficulties with study skills in higher education. Studies in Higher Education, 31(2), 235-251.

Mortimore, T. (1998). A comparision of learning style in dyslexic and non-dyslexic undergraduates. Unpublished M.Ed Dissertation. Cardiff: The University of Cardiff.

Mortimore, T. (2000). Learning style and dyslexia. In Smythe, I. (Ed.) The Dyslexia Handbook 2000 (pp. 142-147). Reading: The British Dyslexia Association.

Mortimore, T. (2005). 'Dyslexia and learning style-a note of caution'. The British Journal of Special Education, 32(3), 145-148.

Mortimore, T. (2008). Dyslexia and Learning Style: A Practitioner's Handbook (2 ${ }^{\text {nd }}$ ed). Chichester: Wiley.

Orton Dyslexia Society (1994). Perspectives in Dyslexia, 30, 5.

Piaget, J. (1970). Piaget's theory. In P.H. Mussen (ed.) Carmichael's Hanbook of Child Psychology (pp. 703-732). New York: Wiley.

Prashnig, B (2004). The power of diversity: new ways of learning and teaching through learning styles, Stafford: Network Educational Press.

Pumfrey, P.D. \& Reason, R. (1991). Specific learning difficulties (dyslexia): Challenges \& responses. London: Routledge.

Reid, G. \& Kirk, J. (2001). Dyslexia in adults: education and employment. Chichester: John Wiley \& Sons Ltd. 
Riddick, B., Farmer, M. \& Sterling, C. (1997). Students and dyslexia: Growing up with a specific learning difficulty. London: Whurr.

Riddick, B., Sterling, C., Farmer, M. \& Morgan, S. (1999). Self-esteem and anxiety in the educational histories of adult dyslexic students. Dyslexia: An International Journal of Research and Practice, 5, 227-248.

Riding, R.J. \& Rayner, S. (1998). Cognitive styles and learning strategies. London: David Fulton.

Riding, R.J. (1991). The Cognitive Styles Analysis. Birmingham: Learning and Training Technology.

Rose, J. (2009). Identifying and Teaching Children and Young People with Dyslexia and Literacy Difficulties. Nottingham: DCSF Publications

Scott, M.E., Scherman, A. \& Phillips, H. (1992). Helping individuals with dyslexia succeed in adulthood: Emerging keys for effective parenting, education and development of positive self-concept. Journal of Instructional Psychology, 19, 197-204.

Singleton, C. H. (Ed.) (1999). Dyslexia in higher education: Policy, provision and practice. Report of the National Working Party on Dyslexia in Higher Education. Hull: The University of Hull.

Soriano, M. (2004). Current perspectives in the study of developmental dyslexia. Electronic Journal of Research in Educational Psychology, 2(2), 1-4.

The British Dyslexia Association (2005). The Dyslexia Handbook. Reading: British Dyslexia Association.

Vinegrad, M. (1994). A Revised Adult Dyslexia Checklist. Educare, 48, 21-23.

West, T. (1997). In the mind's eye: Visual thinkers, gifted people with dyslexia and other learning difficulties, computer images, and the ironies of creativity. Amherst, NY: Prometheus.

Wingate, J. (2000). Knowing me, knowing you. London: Delta Publishing.

Zenakou, E. (2005). The Learning Preferences Test. Paper presented at the $10^{\text {th }}$ Hellenic Conference of Psychological Research. Ioannina: 1-4 December 2005. 